\title{
TURISMO EN EL MUNDO MAYA. FLUJOS DE VISITANTES EN EL SITIO ARQUEOLÓGICO DE COPÁN (HONDURAS) ${ }^{1}$
}

\author{
Manuel de la Calle Vaquero \\ María García Hernández. \\ Universidad Complutense de Madrid
}

\begin{abstract}
RESUMEN
El área maya constituye una importante región turística de América Latina, en especial respecto al turismo cultural. Aunque existe una importante producción científica sobre la zona, pocos trabajos abordan los temas relacionados con la afluencia y perfil de los visitantes. En este artículo se presenta la metodología utilizada para cuantificar y caracterizar el flujo de visita del Parque Arqueológico de Copán en Honduras, detallándose los resultados obtenidos. Se señala en primer lugar las características básicas de la visita (distribución temporal, forma de organización del viaje, etc.). Seguidamente se aborda la identificación de los grandes componentes del flujo de visita, a partir de la consideración conjunta de varios criterios de agrupación. Por último se resalta la importancia de contar con este tipo de datos a efectos de un correcto manejo del uso público y del diseño de estrategias coherentes de desarrollo turístico.
\end{abstract}

Palabras clave: Mundo maya; turismo arqueológico; Copán; flujos de visitantes.

Recibido: 4 de julio de 2014

Devuelto para su revisión: 13 de noviembre de 2014

Aceptado: 16 de diciembre de 2014

Departamento de Geografía Humana. Universidad Complutense de Madrid. C/ Profesor Aranguren, s/n. Ciudad Universitaria. 28040 MADRID (España).E-mail: mcalleva@ghis.ucm.es, mgarciah@ghis.ucm.es

1 Este texto se enmarca dentro del proyecto «La capacidad de carga como instrumento de planificación y gestión de los recursos turístico-culturales», del Ministerio de Ciencia e Innovación (Plan Nacional de I+D+i). Ref: CSO2010-20702 GEOG (2010-2013). Investigadora principal: Dra. María García Hernández. De forma más específica, el área de Copán ha sido objeto de estudio en el marco de una asistencia técnica solicitada a un equipo del Grupo de Investigación «Turismo, Patrimonio y Desarrollo» (http://www.ucm.es/geoturis) por la Oficina Técnica en Honduras de la Agencia Española de Cooperación Internacional y Desarrollo a favor del Instituto Hondureño de Antropología e Historia y el Parque Arqueológico de Copán (2011-2013). 


\title{
Tourism in the Maya World. Archaeological site visitors in Copán (Honduras)
}

\begin{abstract}
The Maya area is an important tourist region for cultural tourism in Latin America. There is substantial scientific literature on the area. However there are few studies about tourist flows and visitor profile. This article describes the methodology used to quantify and characterize the flow of visiting the Archaeological Park of Copán in Honduras. It also details the results. First it notes the basic characteristics of the visit (timing, form of travel arrangements, etc...). Following the identification of the major components of the tourist flow is addressed, from the joint consideration of multiple grouping criteria. Such data are important for the proper management of cultural attractions and also to design coherent strategies for tourism development.
\end{abstract}

Keywords: Maya World; archaeological tourism; Copán; tourist flows.

\section{PRESENTACIÓN. TURISMO EN EL MUNDO MAYA}

John Lloyd Stephens y Frederick Catherwood recorren la zona maya del Yucatán y Centroamérica en el tránsito entre las décadas de 1830 y 1840, dejando constancia de sus experiencias en varios libros de viaje y un conjunto extraordinario de ilustraciones. Con ellos, el mundo maya irrumpe con fuerza en el imaginario colectivo de Occidente, un mundo de templos en forma de pirámide entre selvas tupidas, juegos de pelota y rituales plenos de exotismo. Con el tiempo, las tierras de Belice, Guatemala, Honduras, El Salvador y, dentro de México, de Campeche, Chiapas, Quintana Roo, Tabasco y Yucatán, son objeto de un trabajo sistemático de reconocimiento arqueológico y etnológico, en muchos casos financiado por instituciones norteamericanas y, en mucha menor medida, europeas. En paralelo al crecimiento de estos viajes académicos, empieza a emerger un flujo turístico ciertamente elitista y con fuertes resonancias culturales.

En la actualidad, el área maya constituye una importante región turística de América Latina. El atractivo asociado a este mundo sigue vigente y su presencia en los medios de comunicación de masas es significativa. De hecho, con cierta frecuencia se señala la aparición de un artículo sobre la ruta maya en National Geographic (Garret, 1989) como uno de los detonantes del crecimiento turístico de las últimas décadas. Cronológicamente, este artículo es coetáneo con los Acuerdos de Esquipulas, que sentaron las bases para la pacificación de la región, así como de una mayor cooperación económica entre las repúblicas centroamericanas. Arquetipo de civilización perdida, los vestigios materiales precolombinos son la base de un turismo arqueológico centrado en las grandes ciudades muertas, muchas de ellas incluidas en la Lista del Patrimonio Mundial de la UNESCO. Existe también un turismo de culturas vivas, que busca un contacto más estrecho con las comunidades mayas actuales y se desarrolla fundamentalmente en Chiapas y las tierras altas de Guatemala. Ambas formas de turismo cultural se combinan con prácticas de ecoturismo, visita a las ciudades coloniales e incluso actividades de aprendizaje de idiomas, turismo 
espiritual y solidario. Además la referencia maya actúa de complemento en relación a los desarrollos costeros de Quintana Roo y propicia el atraque de los cruceros que recorren el Caribe. Conscientes del atractivo del referente, organismos internacionales y autoridades nacionales llevan impulsando desde hace décadas planes y programas de desarrollo turístico a distintas escalas. Entidades como la Organización Mundo Maya, conformada en 1992 por los departamentos de turismo de Belice, El Salvador, Guatemala, Honduras y México, han impulsado un conjunto muy amplio de proyectos con financiación del Banco Mundial, el Banco Interamericano de Desarrollo o distintas agencias gubernamentales de cooperación al desarrollo. Más recientemente, las referencias en el calendario maya a un cambio de ciclo en el 2012 han sido utilizadas como reclamo a efectos de alcanzar una mayor proyección turística.

Dentro del ámbito académico, un buen número de trabajos han tratado distintas dimensiones del turismo en relación a la zona, considerada en sentido amplio. Ana García de Fuentes (1979) y Fernando Martí (1985) han relatado los orígenes de Cancún, en la costa de lo que ahora se denomina Caribe mexicano. En fechas más recientes se aborda el desarrollo de la Riviera Maya, con centro en la localidad de Playa del Carmen, y Costa Maya, mucho menos consolidada. Dentro de estos proyectos la referencia maya es una constante, un argumento que sirve para singularizarse respecto a otros destinos del Caribe. Las repercusiones sobre el conjunto de la zona costera de Quintana Roo son de una intensidad extraordinaria y, como no puede ser de otra manera, también implican una afectación cultural (Córdoba y Ordóñez, 2009; Marín Guardado, 2010). El impacto a nivel local ha sido analizado con profusión, ya sea en comunidades directamente impactadas por el desarrollo turístico costero (Juárez, 2002) o en otras comunidades de Quintana Roo y los estados vecinos que están optando por el ecoturismo y otras fórmulas equivalentes (Córdoba y Ordóñez et al., 2004; Daltabuit Godás et al., 2007; Santana et al., 2013). Las referencias se extienden a Chiapas (Hernández Cruz et al., 2005; Van den Berghe, 1995), cuyo funcionamiento turístico resulta en origen autónomo a Cancún, y múltiples trabajos glosan distintos aspectos del Programa Mundo Maya. Dentro de éstos, predomina la orientación antropológica y el debate se centra en los efectos sobre los «living Mayas», con posiciones que se sitúan entre la amenaza directa a la supervivencia cultural de estas comunidades (Brown, 1999) y su adaptación mediante una reinvención constante en tanto que entidades culturales vivas (Magnoni et al., 2007).

Tiene también un tratamiento extenso las temáticas relacionadas con la utilización del patrimonio arqueológico como recurso turístico. En unos casos se llama la atención sobre el uso social de este patrimonio, que incorpora la dimensión turística (García Targa, 2012; Ortega Muñoz, 2010). De forma más específica, se indaga sobre aspectos relativos al impacto turístico y la gestión de la visita pública (Mínguez García et al., 2012; Segrado et al., 2013; Walker, 2005) así como la utilización de determinadas zonas arqueológicas por las comunidades locales con vistas al desarrollo turístico (Tzuz Salinas, 2012). Buena parte de estas referencias se centran en sitios y experiencias de México, aunque también se han generado reflexiones interesantes en torno al Petén en Guatemala (Muñoz Cosme et al., 2003a), con trabajos más centrados en Tikal (Muñoz Cosme et al., 2003b) y otros lugares menos conocidos como Salinas de los Nueve Cerros (Woodfill, 2013) y Succotz (Medina, 2003), éste último en Belice. 
Si bien existe una extensa producción bibliográfica sobre el turismo en relación al mundo maya, los trabajos que indagan específicamente sobre los visitantes son muy escasos. A nivel general, se manejan datos del tránsito de turistas internacionales en fronteras $\mathrm{y}$, si acaso, de viajeros y pernoctaciones en los establecimientos hoteleros de las zonas de mayor desarrollo turístico. De forma más concreta, se recurre a los datos de visita de los grandes centros arqueológicos. Estos datos están especialmente bien recogidos en México. Para 2012, el Instituto Nacional de Antropología e Historia de México cifró la afluencia en Chichén Itza en 1.497.673 personas (924.335 nacionales y 573.338 extranjeros), 1.199.312 en Tulum (489.295 y 710.017), 473.259 en Cobá (86.775 y 386.484), 239.069 en Uxmal (142.545 y 96.524) y 151.809 en San Gervasio (32.652 y 119.157), en la isla de Cozumel. En Chiapas, sin conexión inmediata con el Caribe mexicano, se encuentra Palenque, con 579.658 visitas (450.993 y 128.655). En Guatemala, el INGAUT -a partir de las estadísticas del IDAEH- ha publicado cifras de 128.000 visitantes para Tikal en 2010 (59.600 nacionales y 68.400 extranjeros) y de 104.657 para 2011 (50.201 y 54.456). Las variaciones entre años y fuentes son muy acusadas, lo que hace dudar de la consistencia de los datos. En El Salvador, Joya de Cerén registró 47.351 visitantes en 2012 (38.448 nacionales y 8.903 extranjeros). Para 2006 esta cifra era de 42.072 personas, en un rango similar a la que se registraba en Xunantunich y Altun Ha en Belice (40,3 y 58,2 respectivamente).

Aunque los registros de visita son insuficientes y poco fiables, fundamentalmente en las repúblicas centroamericanas, la práctica totalidad de los trabajos los utilizan como referencia de base. De este nivel muy general se pasa a trabajos de reconocimiento etnográfico exhaustivo sobre sitios muy significativos, con los visitantes (su discurso, su mirada...) como uno de los objetos preferentes de investigación. Resultan especialmente sugerentes las reflexiones de Quetzil E. Castañeda (1995, 1996 y 2009) en base a su trabajo de campo en Chichén Itza. Entre ambos niveles, el básico que utiliza las estadísticas oficiales disponibles y el específico de reconocimiento etnográfico y orientación antropológica, las referencias publicadas para la zona maya son escasísimas y bastante tangenciales. Alejandra Zorrilla (2011) señala la importancia del turismo independiente en la zona, lo que hacía especialmente difícil identificar una posible «ruta maya». Y Enrique Hernández (2012) ha indagado sobre la percepción de los destinos de referente maya en el mercado de turismo organizado francés, a través de encuesta a los principales operadores. También nuestro trabajo sobre los visitantes de Copán, cuyos aspectos básicos se señalan en el epígrafe siguiente, se sitúa en este nivel intermedio, en un intento de generar nuevo conocimiento sobre el flujo de visitas directamente aplicable a la gestión del sitio arqueológico.

\section{EL SITIO ARQUEOLÓGICO DE COPÁN: CARACTERIZACIÓN Y METO- DOLOGÍA DE TRABAJO}

El Valle de Copán se sitúa en las regiones montañosas del occidente de Honduras, en la frontera con Guatemala y en las proximidades de El Salvador. Los mayas penetraron tardíamente en la zona, alrededor del 150 d.C. Dentro del Valle, la zona más densamente poblada correspondía a la urbe de Copán, cuya historia está estrechamente ligada a los 16 gobernantes de la dinastía fundada por K'inich Yax K'uk Mo', quien ascendió al 
poder en el año 426 d.C. El máximo apogeo constructivo y artístico data del reinado de Uaxaklahun Ubah K'awi - 18 Conejo (695-738 d.C.), uno de los gobernantes registrados en el célebre Altar Q. Dentro del perímetro urbano, el núcleo de mayor densidad arquitectónica y monumental corresponde al área conocida como Grupo Principal, centro ceremonial y lugar de residencia de las élites regionales. Anexos al Grupo se situaban tres grandes áreas residenciales: El Cementerio, Las Sepulturas y El Bosque. Río Amarillo (a $20 \mathrm{~km}$ al este de Copán) funcionaba como un centro secundario, un nodo dentro del circuito de comunicación formado entre Copán y Quirigua (en el Valle del Río Motagua, actualmente Guatemala).

\section{Ilustración 1 \\ GRUPO PRINCIPAL: GRAN PLAZA DESDE LA CIMA DE LA ACRÓPOLIS}

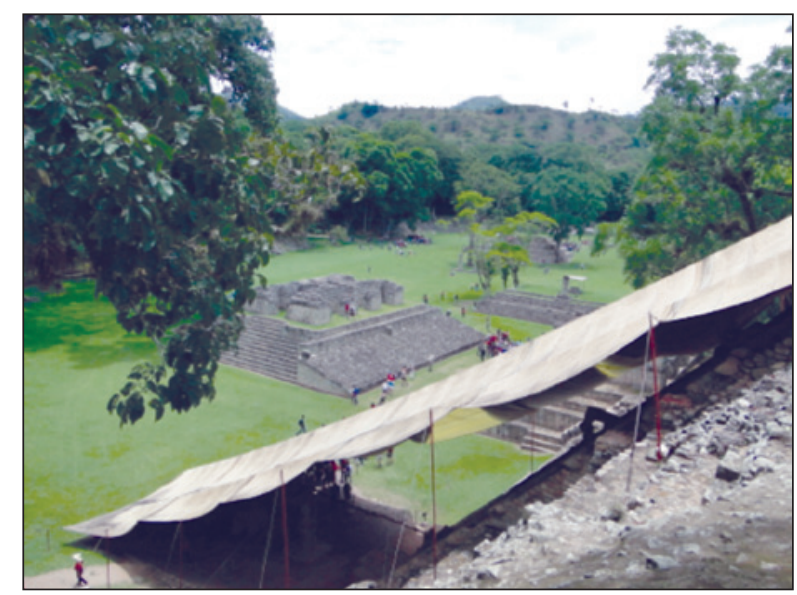

Fuente: Autores del artículo.

Las primeras noticias de la presencia de vestigios corresponden a Diego Palacios en 1570. Entre 1839-1841 Stephens y Catherwood recorren la zona, como atestiguan sus libros de viaje e ilustraciones. Pocos años después y como reacción a la compra de los terrenos que realizó el propio Stephens, el gobierno de Honduras declara el lugar como Zona Nacional de Antigüiedades (1843) y los terrenos como propiedad de la nación (1845). Desde finales del siglo XIX se inicia una labor sistemática de investigación, con fuerte protagonismo de instituciones extranjeras: el Museo Peabody de la Universidad de Harvard, la Institución Carnegie y otras. La localidad actual de Copán Ruinas ya existía como poblado en el año 1839 cuando Stephens llega a la región. Durante buena parte de su historia el crecimiento del núcleo urbano ha estado asociado a la actividad arqueológica. Si en 1945 el pueblo cuenta con 1.045 habitantes, en 1974 ya se contabilizaban 2.306. El resto del municipio, con presencia de cientos de aldeas -muchas habitadas por indígenas de la etnia Chortis- y fuerte peso de la agricultura de subsistencia, presentaba un crecimiento mucho más atenuado debido a la primacía de la emigración. Durante toda esta etapa el turismo es, si acaso, predominantemente «científico». 
La década de los setenta del siglo pasado supone un cambio en las formas de intervención en el sitio. A pesar del escaso desarrollo turístico efectivo, las autoridades hondureñas comienzan a considerar las potencialidades de Copán como vector de proyección cultural y turística del país (Calle Vaquero, 2014). Para ello se solicita asistencia y financiación a los grandes organismos multilaterales: primero el Banco Centroamericano de Integración Económica y después el Banco Mundial (Proyectos Copán I y II). De forma paralela a la intervención arqueológica, se va acometiendo su salvaguarda patrimonial. UNESCO propicia la inclusión del Sitio Maya de Copán en la Lista del Patrimonio Mundial en 1980 y auspicia la elaboración de un primer plan de manejo (Barborak et al., 1984). A nivel nacional, el 24 de junio de 1982 se declara Monumento Nacional todos los restos arqueológicos del Valle del Copán y se establece una zonificación del área central en función de su importancia arqueológica. Para cada zona queda fijado un régimen de usos y un procedimiento de autorizaciones que gravita sobre el Instituto Hondureño de Antropología e Historia (IHAH).

La dotación de fondos externos ha seguido siendo intensa durante los últimos años. A comienzos del siglo el Banco Mundial financia el proyecto PROFUTURO, que incluyó la reparación de las áreas del núcleo monumental que habían sido más dañadas por el huracán Mitch (1998) y la actualización del plan de manejo por parte de la Wildlife Conservation Society (IHAH, 2005). Posteriormente, aprueba una préstamo de 12 millones de dólares para financiar el Proyecto de Desarrollo Regional del Valle de Copán 2003-2009 (PDRVC), de enfoque más amplio. De forma paralela, la administración turística del país impulsa el Proyecto de Turismo Sostenible Mundo Maya que forma parte del Programa Regional Mundo Maya financiado en una de sus fases por el Banco Interamericano de Desarrollo.

En este contexto se gesta el trabajo de base que sustenta este artículo. Dentro de los últimos proyectos referidos se incluía la construcción de un aeródromo en el Valle de Copán, siguiendo el modelo del aeropuerto de Flores en relación a Tikal. Dicha acción se considera prioritaria a nivel de país, ya que permitiría mejorar el posicionamiento de Copán tanto en relación al turismo de base patrimonial (zona maya) como al flujo de visitantes extranjeros que llegan a Honduras por motivos de negocio (Tegucigalpa y San Pedro Sula) o en cruceros (Islas de la Bahía). El previsible impacto generado sobre la zona activa los mecanismos de respuesta del Centro del Patrimonio Mundial de la UNESCO, que envía diferentes misiones de reconocimiento y trata el tema dentro de sus sesiones ordinarias. Además de los efectos de las iniciativas en curso en el Valle, se cuestiona el modelo global de gestión del Parque Arqueológico y su capacidad para absorber el flujo turístico adicional derivado de la construcción del aeródromo ${ }^{2}$. En este sentido, desde la

2 El debate que cuestiona el modelo de gestión del sitio se abre a partir de la preocupación de arqueólogos y patrimonialistas por las altas expectativas de crecimiento de los flujos de visita que genera la construcción del aeródromo. Aunque a grandes rasgos no existen graves problemas de presión turística sobre el conjunto, se es consciente de que el crecimiento de la afluencia turística supondría agravar sobremanera problemas puntuales de uso público no resueltos hasta la fecha como son: agresión y deterioro patrimonial los días de máxima afluencia en determinados espacios (culmen de la estructura 11 de la Acrópolis, túneles, inmediaciones de la escalera jeroglífica y juego de pelota), mal comportamiento de escolares (la categoría de visitantes más «agresivos» con el patrimonio) o desbordamiento de los servicios de acogida (área de aparcamiento, punto de venta de entradas, colas en los accesos al grupo principal, etc...), insuficientemente dotados para momentos álgidos de visita. 
administración del Parque se plantea la elaboración de un estudio de capacidad de carga turística y la inclusión de sus resultados en la actualización del plan de manejo, para lo que se contó con financiación de la Agencia Española de Cooperación y Desarrollo.

Un estudio de capacidad de carga como el que se desarrolló en Copán ${ }^{3}$ debe basarse necesariamente en un conocimiento exhaustivo de los visitantes (García Hernández, 2012; Santos et al., 2013). Como se ha señalado antes para el conjunto de la zona maya, en Copán este conocimiento presenta dos niveles de muy diferente alcance, aunque en ambos casos se centran en el Parque Arqueológico, el espacio de mayor concentración monumental articulado en torno al Sitio Patrimonio Mundial y de gestión directa por el IHAH. Un primer nivel de información corresponde a las estadísticas de visita disponibles, cuyos datos derivan de un Libro de Registro Nominal situado en la entrada del Grupo Principal. En dicho Libro los visitantes procedían a estampar su firma indicando su lugar de residencia. Además se contaba con los datos del sistema de taquillas, que recoge las operaciones de venta de billetes por tarifa. Aunque ofrece información más detallada de la distribución temporal de las visitas y el uso de las diferentes partes del Parque, refleja potencialidades de visita más que visitas efectivamente realizadas (por ejemplo, la entrada de un visitante nacional permite acceder a la zona de Sepulturas, pero no queda constancia de que se haya accedido o no). De hecho las cifras de ambas fuentes no concordaban. El segundo nivel de información, basado en un reconocimiento etnográfico exhaustivo y de orientación antropológica, está muy bien representado en los trabajos de Lena Mortensen (2001, 2009 y 2011). Al igual que hace Quetzil E. Castañeda en Chichén Itza, esta autora narra los conflictos generados en torno al Parque Arqueológico, un campo en disputa por diferentes actores (municipalidad, administradores del IHAH de ámbito local, regional y nacional, guías, vendedores, organizaciones chortís... y también los visitantes en toda su heterogeneidad) que articulan distintos discursos sobre Copán. El punto de partida es el desarrollo de un potente foco de arqueoturismo en un área muy deprimida, de ahí en el interés por apropiarse de los beneficios asociados al Parque ya sea de forma directa (ingresos por entradas) o indirectas (concesiones y equivalentes).

Entre estos dos niveles existía un vacío muy notable de información ${ }^{4}$, lo que impedía el desarrollo del estudio de capacidad de carga. De forma más general, la ausencia de

3 La necesidad de elaboración de un estudio de capacidad de carga turística en Copán se venía mencionando en varios documentos y se encuentran algunas referencias sueltas a estimaciones parciales realizadas bajo diferentes enfoques metodológicos en el Plan de Manejo de Copán de 2005 o en el Estudio de la redistribución óptima de los ingresos del Parque Arqueológico de Copán, también del año 2005. El presente Estudio de Capacidad de Carga (realizado por la UCM) parte del presupuesto de que, como cualquier otro sitio patrimonial musealizado, en el PAC el análisis en profundidad de esta temática presenta tres dimensiones: una dimensión física que hace referencia al volumen total de personas que la extensión del espacio acondicionado para la visita puede contener en un determinado momento sin que se ponga en peligro la conservación de los elementos patrimoniales (capacidad de carga física del conjunto), una dimensión psico-social que está relacionada con la calidad de la experiencia de visita de todas aquellas personas que se acercan a conocer el sitio (capacidad de carga perceptual) y una dimensión «operativa» que tiene que ver con la disponibilidad de medios (humanos y económicos) con que se cuenta para gestionar los flujos de visitantes en destino.

4 El Estudio de la Redistribución de los Ingresos del Parque Arqueológico de Copán (2005), elaborado por Arden \& Price Consulting y TURPLAN en el marco del PDRVC, aporta datos de una encuesta a 240 visitantes realizada entre el 11 y 14 de marzo de 2005. El Plan de Interpretación para el Monumento Nacional Ruinas Copán (2006), redactado por Heritage Design también dentro del PDRVC, da cuenta de un informe sobre la visita 
«datos intermedios» estaba limitando la capacidad de manejo del uso público de la zona arqueológica y dificultaba sobremanera establecer estrategias coherentes de desarrollo turístico a nivel municipal y regional. Para solventar estos problemas y a efectos de profundizar en el conocimiento de los visitantes, en el marco del Estudio sobre Capacidad de Carga Turística del Parque Arqueológico de Copán (2011-2013)5 se diseñó un conjunto de operaciones de recogida de datos que cubrían diferentes aspectos relacionados con la visita y el uso público del área (conteo de vehículos, estudios sobre duración de la visita, etc.). Dentro de estas operaciones, destaca la elaboración y puesta en marcha de un nuevo Sistema de Cómputo de Visitas al Grupo Principal que sustituye al antiguo Libro de Registro de carácter nominal. El nuevo Sistema recoge información sobre cada «grupo de viaje», entendido como cada persona o agrupación de personas que realizan el desplazamiento en común. Por lo tanto esta unidad de registro puede corresponder tan solo a una persona, a varios visitantes juntos en forma de familia, grupo de amigos... a un grupo de un operador turístico, un colegio, etc. Como se hacía en el Libro de Registro, la información se recoge en el acceso al Grupo Principal, de acuerdo a un formato de ficha estandarizada ahora cumplimentada por el personal del Parque.

\section{Figura 1}

\section{PARQUE ARQUEOLÓGICO DE COPÁN: FICHA DE REGISTRO DE VISITA PARA GRUPO DE VIAJE}

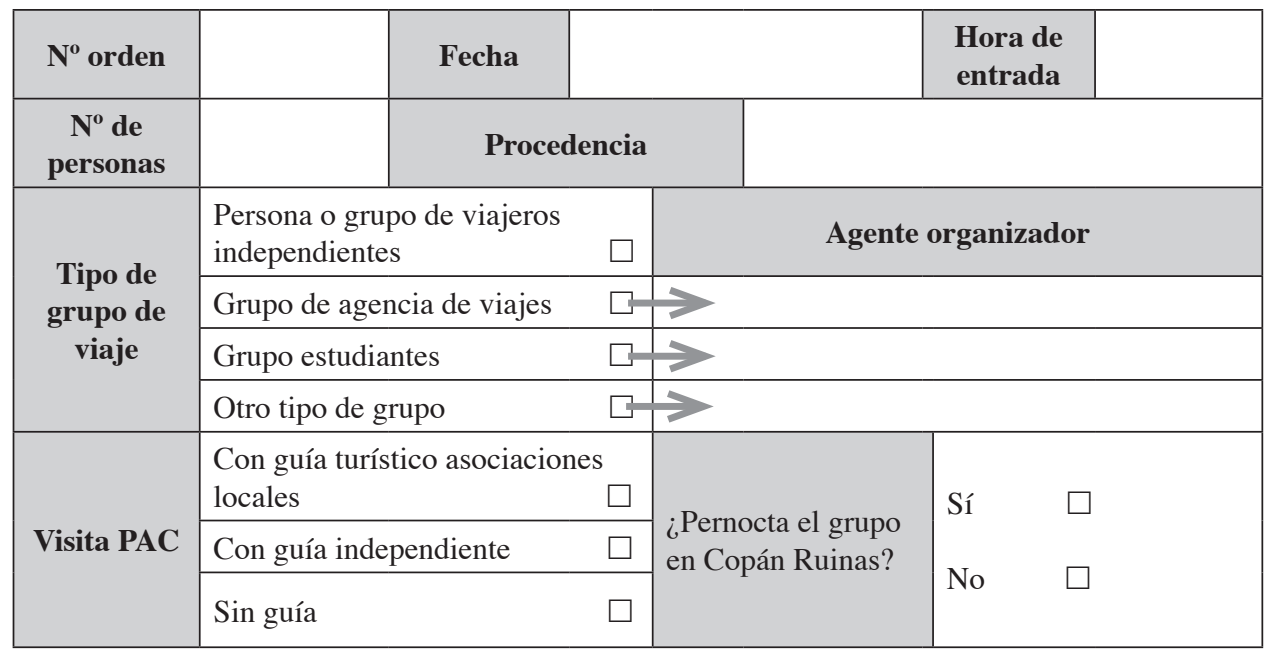

Fuente: Elaboración propia.

realizado en 2003 por Christopher Mayer. Aspectos como el escaso tamaño de la muestra y la concentración temporal del periodo de realización limitan la representatividad de los resultados, que aparecen muy sesgados a favor del viajero extranjero independiente.

5 García Hernández, M. (dir.) (2013). Estudio de Capacidad de Carga Turística del Parque Arqueológico de Copán. Instituto Hondureño de Antropología e Historia - Oficina de Cooperación Española en Honduras. Estudio elaborado por miembros del Grupo de Investigación «Turismo, patrimonio y desarrollo» de la Universidad Complutense de Madrid (proyecto inédito). 
Esta ficha (Figura 1) permite obtener bastante información sobre los visitantes con un esfuerzo reducido. De cada «grupo de viaje» queda registrado la fecha, hora de entrada, número de personas y procedencia, a nivel de país para los extranjeros y de departamento y municipio para los nacionales. Un segundo bloque de contenidos se centra en la caracterización del «grupo», atendiendo a la condición de viajeros independientes, grupos de agencia de viaje, grupos de escolares / estudiantes, y otros grupos (religiosos, culturales, etc.). Si se trata de un viaje colectivo, se solicita la identificación del agente organizador. Y el tercer bloque permite identificar si la visita se realiza con o sin guía, y si se pernocta o no en Copán Ruinas.

El nuevo Sistema de Cómputo basado en las fichas de registro se empezó a implantar a comienzos del año 2013, una vez ajustado en campo y entrenado el personal responsable del Parque. Con el nuevo sistema, a lo largo del 2013 se registró la presencia de 15.663 «grupos de viaje», de los que 5.198 correspondían a hondureños y 10.4677 a extranjeros. Los datos recogidos han sido volcados a una base digital por parte del personal del IHAH, una base de 15.663 registros que tuvo que ser notablemente depurada para eliminar los errores de transcripción y mejorar la estandarización de los datos. En última instancia, se procedió a principios de 2014 a la explotación de estos datos, conformando uno de los apartados del estudio de capacidad de carga del área de Copán.

\section{CARACTERÍSTICAS BÁSICAS DE LA VISITA}

Como se ha señalado anteriormente, el nuevo Sistema de Cómputo de Visitas del Grupo Principal ha permitido obtener un conocimiento mucho más detallado de los visitantes del Parque Arqueológico de Copán que el que se tenía con anterioridad. En los epígrafes siguientes se presenta una síntesis de resultados atendiendo a la procedencia de los visitantes, su distribución temporal, fórmula de viaje, utilización de los servicios de guías turísticos y pernoctación en el municipio. Aunque se ha procedido al cruce de algunas variables, la dimensión más interpretativa se deja para el apartado siguiente, centrado en la caracterización de los grandes componentes del flujo de visita.

\subsection{Lugares de procedencia}

De las 112.477 visitas contabilizadas durante 2013, 59.352 corresponden a hondureños $(52,76 \%)$ y 53.125 a extranjeros $(47,23 \%)^{6}$. Dentro de cierto margen, se trata de una distribución bastante estable durante los últimos años, una distribución que contrasta con la situación registrada durante los años iniciales de activación turística de la zona arqueológica. Los primeros datos de visita de que se disponen apuntaban a un notable predominio de los extranjeros, que accedían a Copán como una parada en un circuito más amplio por las tierras mayas de Guatemala. El Plan de Manejo y Desarrollo de 1984 indica que de

6 A efectos de contextualizar estas cifras, cabe señalar que para 2013 el Instituto Hondureño de Turismo contabilizó 0,86 millones de turistas extranjeros que pernoctaron en el país, a los que hay que añadir otros 0,99 millones de excursionistas, en su mayor parte cruceristas. No existen datos relativos al turismo interno. Dentro de Honduras, Copán es, con mucha diferencia, el referente cultural más visitado, a gran distancia de lugares como el Castillo de San Fernando de Omoa (24.127 visitas en 2013), el Museo Arqueológico de Comayagua (16.662), la Fortaleza de Santa Bárbara (13.842) o las Cuevas de Talgua (9.753). 
los 26.281 visitantes registrados en 1978 el 62,73\% eran extranjeros y tan solo el 37,37\% nacionales. La mejora de la carretera que une las localidades de La Entrada y Copán Ruinas favoreció sobre todo una mejor accesibilidad respecto al resto de Honduras, lo que se tradujo en un incremento muy importante del turismo interno. En todo caso la tendencia general observada durante los últimos quinquenios apunta a una mayor representación de los hondureños dentro de la afluencia global, en porcentajes variables también en función de diversas circunstancias. De acuerdo a los datos del antiguo Libro de Visitas del Grupo Principal, para el periodo 1995-2012 los visitantes nacionales representaron el 47,72\% de la afluencia registrada. De forma más específica, aportaron el 49,6\% del flujo de visita durante 2010, el 47,79\% en 2011 y el $54,11 \%$ en 2012 .

A pesar de la fuerte presencia del turismo interno, a nivel local sigue produciéndose una notable equiparación de la figura del turista con el visitante extranjero, en una lógica del turismo como sector generador de divisas. Como se ha señalado anteriormente, para 2013 se contabilizaron 53.125 visitas de extranjeros. En el nuevo sistema de registro se identificaron personas de más de 90 nacionalidades, aunque la afluencia se concentraba en tres áreas emisoras:

- Europa, que aportó el 42,32\% de los visitantes extranjeros y el 19,94\% de la afluencia total. Los países con mayor presencia fueron Francia (6.341) y, a bastante distancia, Reino Unido (2.791), Alemania (2.219), España (2.038), Holanda (1.697) e Italia (1.679).

- Norteamérica, en especial Estados Unidos. Durante 2013 se registró la visita de 12.957 personas de este país, equivalentes al $24,44 \%$ de la afluencia extranjera y el $11,51 \%$ del flujo global.

- Centroamérica, fundamentalmente las repúblicas vecinas a Copán: Guatemala y El Salvador. Para 2013 el área sumó 8.204 visitas, el 15,48\% de las visitas de extranjeros y el 7,29\% de la afluencia total.

Durante ese mismo año, los hondureños acumularon 59.447 visitas. El nuevo sistema de registro establecido en el Grupo Principal recoge por primera vez la procedencia de estos visitantes, aspecto hasta ahora desatendido debido a la prevalencia otorgada al turismo internacional. En líneas generales, la distribución geográfica del turismo interno viene condicionada por la potencia demográfica de los mercados de origen y la conectividad entre dichos mercados y el sitio de Copán. Durante el año considerado, el nivel de afluencia más elevado corresponde al Departamento de Cortés (17.988, el 30,31\% de los visitantes hondureños), donde se ubica San Pedro Sula, el área urbana más potente conectada directamente con Copán. En un segundo nivel se sitúan los departamentos de Francisco Morazán (9.551, el 16,09\%) y Copán (11.123, un 18,74\%). El primero acoge Tegucigalpa, capital de la República y aglomeración más poblada del país. El segundo, que corresponde al propio departamento donde se ubica el área arqueológica de Copán, aporta un elevado flujo de visitas de proximidad, tanto los municipios más próximos al Parque (Copán Ruinas, Santa Rita, El Paraíso...) como de aquellos de mayor peso demográfico (Santa Rosa de Copán, Nueva Arcadia...). En conjunto, estos tres departamentos aportan el $64,14 \%$ de las visitas al Parque correspondientes a los hondureños, distribuyéndose el resto entre un número muy elevado de municipios repartidos por todo el territorio nacional. 


\subsection{Distribución temporal de las visitas}

La distribución temporal de los visitantes se caracteriza por una elevada irregularidad, con periodos de fuerte presión frente a etapas de afluencia apenas testimonial. Esta irregularidad se manifiesta primeramente a nivel mensual. Los meses de afluencia más elevada fueron agosto $(12,46 \%)$, julio $(11,20 \%)$ y junio $(10,00 \%)$. Además se registra un máximo secundario asociado a la Semana Santa, que durante 2013 cayó en Marzo (9,58\%). En sentido contrario, la menor presencia de visitantes se registró en septiembre $(4,56 \%)$ y octubre $(6,39 \%)$.

La irregularidad se acentúa a nivel diario. La primera parte de la semana registra una afluencia reducida. Así, las visitas en lunes representan el 7,90\% del total, en martes el $9,57 \%$ y en miércoles el $8,99 \%$. El resto de días de la semana duplican estos valores: un $15,98 \%$ los jueves, $16,06 \%$ los viernes, $22,59 \%$ los sábados y 17,83\% los domingos. Estos datos suponen que las visitas en sábado triplican las visitas de los lunes, lo que implica considerables dificultades para la gestión del Sitio.

Tabla 1

PARQUE ARQUEOLÓGICO DE COPÁN: PROMEDIOS DIARIO DE VISITA 2013

\begin{tabular}{|c|c|c|c|}
\hline Mes & Promedio Visitas / Día & Día & Promedio Visitas / Día \\
\hline Enero & 316,16 & Lunes & 170,83 \\
\hline Febrero & 293,36 & Martes & 206,94 \\
\hline Marzo & 384,89 & Miércoles & 198,33 \\
\hline Abril & 269,10 & Jueves & 352,37 \\
\hline Mayo & 229,03 & Viernes & 347,33 \\
\hline Junio & 374,77 & Sábado & 488,67 \\
\hline Julio & 406,45 & Domingo & 409,13 \\
\hline Agosto & 452,03 & \multirow{5}{*}{\multicolumn{2}{|c|}{$\begin{array}{l}\text { Casillas resaltadas, periodos con valores superiores al } \\
\text { promedio anual. }\end{array}$}} \\
\hline Septiembre & 171,10 & & \\
\hline Octubre & 231,77 & & \\
\hline Noviembre & 318,13 & & \\
\hline Diciembre & 283,68 & & \\
\hline Total & 310,71 & Total & 310,71 \\
\hline
\end{tabular}

Fuente: IHAH - Registro de Visitas del PAC Copán - Grupo Principal. Elaboración propia.

Si se divide las 112.477 visitas registradas entre los 362 días en los se recogieron datos, se obtiene un promedio de 310,71 visitas al día. Esta cifra se supera ampliamente tanto en determinados meses (agosto 452,03; julio 406,45; y marzo 384,89) como a nivel de días de la semana (sábados 488,67; y domingos 409,13). De forma más específica, la visita al Parque Arqueológico de Copán adquiere su mayor intensidad en tres periodos temporales de diferente significado:

- Semana Santa. En los nueve días que transcurrieron entre el sábado 23 y domingo 31 de marzo se contabilizaron 5.594 visitas, el 4,97\% de la afluencia del periodo (promedio de 621,55). 
- La segunda quincena de julio y el conjunto del mes de agosto. A nivel global, entre el jueves 17 de julio y el sábado 31 de agosto se registraron 20.593 visitas, el 18,30\% (promedio de 447).

- Los fines de semana repartidos a lo largo del año. En sábados y domingos se contabilizaron 46.686 visitas, el 41,51\% del total (promedio de 448,9).

De hecho, la práctica totalidad de los días de mayor afluencia se sitúan en el marco de estos tres periodos. El mayor número de visitantes se registró el jueves 29 de agosto, una cifra récord de 1.947 visitas. También se contabilizó más de 1.000 visitas el sábado 22 de junio (1.128), el jueves 25 de julio (1.128) y el sábado 10 de agosto (1.010). Y entre las 900 y 1.000 visitas se posicionaron el domingo 21 de julio (978) y, dentro de la Semana Santa, el jueves 28 (925) y el viernes 29 de marzo (920). En sentido contrario, durante 2013 hubo 130 días en los que se registraron menos de 200 visitas por día. En estos 130 días, que representan el 35,91\% del periodo de apertura del Parque, tan sólo se contabilizaron 17.325 visitas, el $15,4 \%$ de la afluencia anual. El mínimo anual de 2013 se corresponde con el lunes 20 de mayo, con tan solo 47 visitas, aunque existe un elevado número de días en los que no se alcanzaron las 100. En suma, una afluencia muy irregular, con un número reducido de días con una notable presión turística que contrasta con un conjunto muy amplio de días en los que el número de visitantes es bastante escaso.

Figura 2

PARQUE ARQUEOLÓGICO DE COPÁN: DISTRIBUCIÓN DIARIA DE LA VISITA AL GRUPO PRINCIPAL 2013

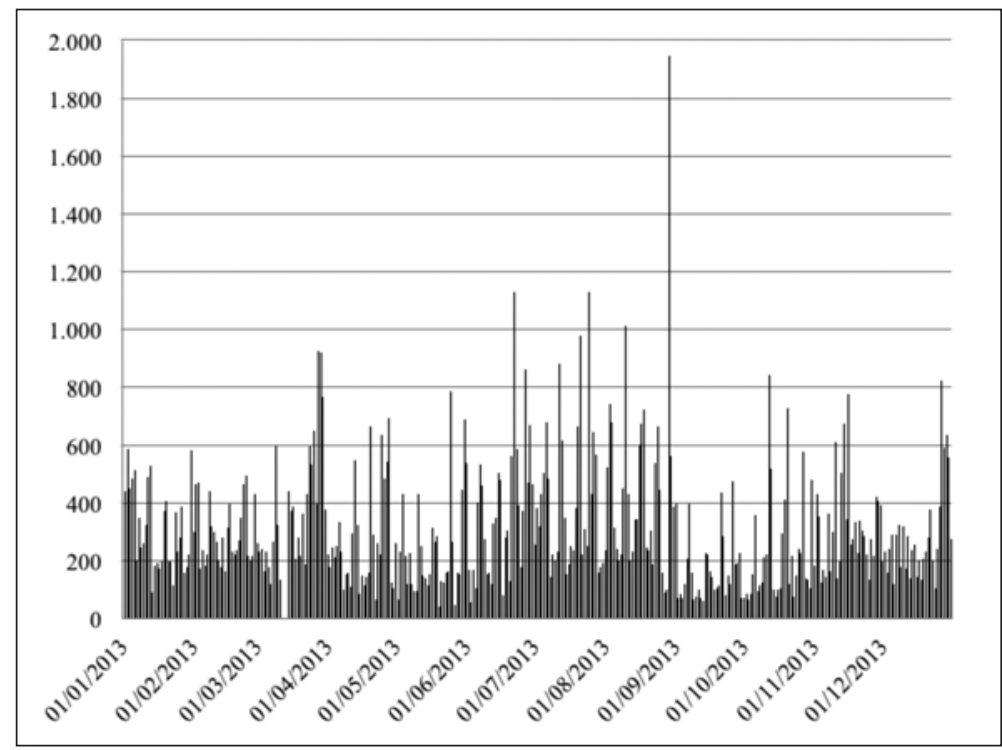

Fuente: IHAH - Registro de Visitas del PAC Copán - Grupo Principal. Elaboración propia. 


\subsection{Fórmulas de viaje}

Dentro de las fórmulas de viaje, el nuevo Sistema de Cómputo implantado en el Grupo Principal permite diferenciar entre visitantes en viaje independiente y visitantes en grupo organizado. Los primeros, que sumaron 59.215 visitas durante 2013 (52,64\% de la afluencia total), viajan solos, en pareja, con familia y/o amigos, generalmente en grupos no muy numerosos. Nacionales y extranjeros presentan cifras muy igualados y la distribución temporal no presenta muchos contrastes, aunque las diferencias en cuanto a mercados sí están más acentuadas (concentración de los hondureños en fines de semana y periodos como la Semana Santa...).

Respecto a los visitantes en grupo organizado, sumaron en 2013 un total de 53.262 visitas (el 47,35\% restante). Como característica común, se trata de viajes colectivos en los que se recurre al desplazamiento en autobús discrecional y/o furgoneta. En un nivel más de detalle, dentro de estos grupos organizados cabe diferenciar dos situaciones: de una parte los grupos comerciales o grupos de agencia $(22.499-20,01 \%)$; y de otra, los grupos no comerciales o grupos institucionales y asociativos $(30.763-27,35 \%)$, buena parte de los cuales se integran dentro del ámbito del turismo social, con fuerte peso de las instituciones educativas. Los primeros derivan de la acción de los touroperadores-agencias de viaje, en tanto que se corresponden con grupos montados a partir de la adquisición individualizada de un paquete turístico en una agencia minorista; el grupo se monta a partir de cada una de estas compras. Son productos utilizados mayoritariamente por los turistas extranjeros y tienen especial presencia durante la temporada seca, de temperaturas más suaves y ausencia de precipitaciones (y de riesgo de huracanes). El segundo tipo corresponde a los grupos no comerciales, conformados por la acción de un conjunto amplio de entidades que impulsan el viaje sin una finalidad estrictamente comercial. Dentro de estas entidades destaca el peso de las instituciones educativas (colegios, institutos, universidades y otros centros de formación), que recurren al viaje como fórmula de aprendizaje in situ. La práctica totalidad de estos grupos son nacionales y su distribución temporal está condicionada por el calendario de cada nivel educativo.

\section{Tabla 2 \\ PARQUE ARQUEOLÓGICO DE COPÁN: DISTRIBUCIÓN DE LAS VISITAS POR FÓRMULA DE VIAJE 2013}

\begin{tabular}{|c|c|c|c|c|}
\hline \multicolumn{2}{|c|}{ Fórmula de Viaje } & Número & $\begin{array}{l}\text { Porcentaje } \\
\text { respecto } \\
\text { total }\end{array}$ & $\begin{array}{c}\text { Porcentaje } \\
\text { respecto viajes } \\
\text { colectivos }\end{array}$ \\
\hline \multicolumn{2}{|c|}{ Visitantes en viaje independiente } & 59.215 & 52,64 & - \\
\hline \multirow{3}{*}{$\begin{array}{l}\text { Visitantes en viaje } \\
\text { colectivo o grupo } \\
\text { organizado }\end{array}$} & En grupo de agencia de viajes & 22.499 & 20,00 & 42,24 \\
\hline & $\begin{array}{l}\text { En grupos escolares o } \\
\text { equivalentes }\end{array}$ & 30.763 & 27,35 & 57,75 \\
\hline & Total & 53.262 & 47,35 & 100,00 \\
\hline \multicolumn{2}{|l|}{ Total visitantes } & 112.477 & 100,00 & - \\
\hline
\end{tabular}

Fuente: IHAH - Registro de Visitas del PAC Copán - Grupo Principal. Elaboración propia. 


\subsection{Visita libre vs. Visita guiada.}

Una vez los visitantes adquieren su boleto / billete para entrar en el Grupo Principal, pueden realizar la visita de forma libre o con un guía turístico, cuyos servicios se contratan de forma ajena a la administración del Parque aunque su actividad dentro del mismo está regulada por una normativa específica del Instituto Hondureño de Antropología e Historia. Para 2013, 37.618 hicieron la visita libre $(33,45 \%)$ y 74.859 con guía (el 66,55\% restante). De éstas, 69.934 recurrieron a los servicios de las asociaciones de guías locales (la Asociación de Guías Copán e Itzat Ahuau, una escisión reciente de la anterior) y 4.925 con otros guías habilitados.

Tabla 3

\section{PARQUE ARQUEOLÓGICO DE COPÁN: DISTRIBUCIÓN DE LAS VISITAS} (\%) POR PROCEDENCIA Y FÓRMULA DE VIAJE 2013

\begin{tabular}{|c|c|c|c|}
\hline \multicolumn{2}{|l|}{ Procedencia } & Visita guiada (\%) & Visita libre (\%) \\
\hline \multicolumn{2}{|l|}{ Honduras } & 61,50 & 38,50 \\
\hline \multirow{6}{*}{ Extranjero } & Centroamérica & 47,34 & 52,66 \\
\hline & Europa & 78,86 & 21,14 \\
\hline & Norteamérica & 78,62 & 21,38 \\
\hline & Resto de América & 67,00 & 33,00 \\
\hline & Resto del Mundo & 65,91 & 34,09 \\
\hline & Total & 72,21 & 27,79 \\
\hline \multicolumn{2}{|c|}{ Fórmula de Organización Viaje } & Visita guiada $(\%)$ & Visita libre (\%) \\
\hline \multicolumn{2}{|c|}{ Agencia de viaje } & 99,14 & 0,86 \\
\hline \multicolumn{2}{|c|}{ Grupos escolares o equivalentes } & 89,26 & 10,74 \\
\hline \multirow{3}{*}{ Independientes } & Hondureños & 33,91 & 66,09 \\
\hline & Extranjeros & 50,90 & 49,10 \\
\hline & Total & 42,38 & 57,62 \\
\hline \multicolumn{2}{|l|}{ Total } & 66,55 & 33,45 \\
\hline
\end{tabular}

Fuente: IHAH - Registro de Visitas del PAC Copán - Grupo Principal. Elaboración propia.

Frente a lo que sucede en Europa, el recurso a la visita guiada es elevado en relación a todos los mercados de origen. De los hondureños, el 61,5\% lo hicieron con guía turístico, porcentaje que asciende al 72,21\% de los extranjeros. Respecto a la forma de organización del viaje, cabe resaltar la estrecha asociación entre la visita guiada y las fórmulas de viaje colectivo. Así, el 99,14\% de los visitantes en viaje organizado por un operador turístico recurren a la visita guiada. De igual forma, el 89,26\% de las visitas en grupos escolares o equivalentes hacen uso de los servicios de un guía para visitar el Parque Arqueológico. No cabe duda de que se trata de cifras muy elevadas, lo que denota la importancia de los guías de Copán como principal fuente de información «in situ» del PAC así como principal canal de mediación entre los gestores del Parque y sus visitantes. 


\subsection{Turistas vs. Excursionistas}

El nuevo Sistema de Cómputo del Grupo Principal indaga sobre la pernoctación en el municipio de Copán, diferenciando entre los excursionistas que no pernoctan y los turistas que pasan al menos una noche en un establecimiento del municipio. De los 112.477 visitantes contabilizados en 2013, 65.899 (58,59\%) afirmaron que habían pasado una noche en un establecimiento turístico radicado en Copán mientras que 46.578 (el 41,41\% restante) habían visitado la zona arqueológica sin pernoctar en el municipio. Estos últimos, los excursionistas en términos de la OMT, pueden corresponder a distintas situaciones: primeramente, personas residentes en el entorno amplio del Parque que realizan una visita en el marco de sus actividades educativas, culturales y/o de ocio más o menos cotidianas, siempre regresando a pasar la noche en su propio domicilio; en segundo lugar, personas en viaje turístico que realizan una excursión a Copán desde su lugar principal de vacaciones, ya sea Guatemala, San Pedro Sula u otras localidades de la costa atlántica hondureña; y en tercer lugar, personas en un viaje turístico de tipo itinerante, generalmente circuitos amplios por Guatemala y, en menor medida, Honduras que incluyen la visita a Copán pero no la pernoctación en el municipio.

Tabla 4

PARQUE ARQUEOLÓGICO DE COPÁN: TURISTAS Y EXCURSIONISTAS EN COPÁN (\%) POR PROCEDENCIA Y FÓRMULA DE VIAJE 2013

\begin{tabular}{|c|c|c|c|}
\hline \multicolumn{2}{|l|}{ Procedencia } & Turistas (\%) & Excursionistas (\%) \\
\hline \multicolumn{2}{|l|}{ Honduras } & 38,19 & 61,81 \\
\hline \multirow{6}{*}{ Extranjero } & Centroamérica & 48,06 & 51,94 \\
\hline & Europa & 90,66 & 9,34 \\
\hline & Norteamérica & 84,53 & 15,47 \\
\hline & Resto de América & 80,98 & 19,02 \\
\hline & Resto del Mundo & 88,74 & 11,26 \\
\hline & Total & 81,38 & 18,26 \\
\hline \multicolumn{2}{|c|}{ Fórmula de Organización Viaje } & Turistas $(\%)$ & Excursionistas (\%) \\
\hline \multicolumn{2}{|c|}{ Agencia de viaje } & 88,32 & 11,68 \\
\hline \multicolumn{2}{|c|}{ Grupos escolares o equivalentes } & 35,21 & 64,79 \\
\hline \multirow{3}{*}{ Independientes } & Hondureños & 42,35 & 57,65 \\
\hline & Extranjeros & 76,63 & 23,37 \\
\hline & Total & 59,44 & 40,56 \\
\hline \multicolumn{2}{|l|}{ Total } & 58,59 & 41,41 \\
\hline
\end{tabular}

Fuente: IHAH - Registro de Visitas del PAC Copán - Grupo Principal. Elaboración propia.

Como se ha señalado anteriormente, cabe considerar el 58,59\% de los visitantes al Parque Arqueológico como turistas de Copán. Si se atiende a los mercados de origen, esta cifra es ampliamente superada por los extranjeros, un $81,38 \%$, más del doble que el porcentaje asociado a los hondureños, un $38,19 \%$. Y dentro de los extranjeros, los valores 
más elevados corresponden a los mercados de larga distancia: Europa con un 90,66\%, Norteamérica 84,53\%, Resto de América 80,98\% y Resto del Mundo 88,74\%. En cambio, los centroamericanos, con un 48,06\% de sus visitantes que pernoctan en Copán, tienen un comportamiento mucho más similar a los hondureños.

En cuanto a las fórmulas de viaje, las diferencias son mucho más acusadas. En un extremo se sitúan las visitas en grupo organizado por los operadores turísticos, que en un $88,32 \%$ pernoctan en Copán. En el extremo opuesto están los grupos escolares y equivalentes, con únicamente el 35,21\% de los visitantes en esta fórmula de viaje que pasan la noche en el municipio. Los visitantes en viaje independiente presentan un valor más similar al promedio, un 59,44\% turistas en Copán y el 40,56\% restante excursionistas. Incluso dentro de los viajeros independientes el recurso a la pernoctación en Copán es más elevado dentro de los extranjeros $(76,63 \%)$ que en relación a los nacionales $(42,35 \%)$.

\section{LOS GRANDES COMPONENTES DEL FLUJO DE VISITANTES}

Antes de la realización del proyecto sobre capacidad de carga en Copán, el conocimiento sobre los visitantes del Parque era bastante reducido. La implantación del nuevo Sistema de Cómputo en el Grupo Principal ha permitido obtener datos mucho más afinados sobre distribución temporal, utilización de los servicios de los guías turísticos, pernoctación..., tal y como se ha mostrado en el apartado anterior. De estos parámetros, a efectos de descomponer el flujo de visitantes del Parque resulta especialmente relevante tomar en consideración conjunta procedencia y fórmula de viaje. Así es posible identificar cuatro grandes tipos de visitantes: 1. Hondureños y otros centroamericanos en viaje independiente; 2. Escolares / estudiantes hondureños en viaje colectivo; 3. Extranjeros en viaje independiente de larga distancia; y 4. Extranjeros en grupo organizado de agencia de viajes. En conjunto, representan el 96,59\% de la afluencia registrada al Grupo Principal durante 2013. Fuera quedan por tanto agrupaciones mucho menos numerosas, como son los extranjeros en viaje de estudios, los visitantes nacionales en grupo de agencia de viaje, los viajes también en grupo de entidades no educativas y otros colectivos también con presencia reducida.

\subsection{Hondureños y otros centroamericanos en viaje independiente}

Los hondureños y otros centroamericanos en viaje independiente conforman el grupo más numeroso, el 32,49\% para el año considerado (26,4\% nacionales y 6,09\% del resto de Centroamérica, especialmente Guatemala y El Salvador). La mayor parte de estos visitantes viajan en su propio vehículo, ya sea desde localidades más o menos cercanas al Parque o desde las áreas más pobladas del país. De hecho el origen del flujo de visita se concentra en los departamentos de Copán, Cortés y Francisco Morazán, con una presencia testimonial de los viajeros del resto de la república. Cuando el viaje es de corto recorrido, responde a actividades de ocio más o menos cotidiano. Conforme la distancia se va incrementando, se tienden a conformar desplazamientos de turismo interno cada vez más complejos en los que Copán siempre suele ocupar una posición relevante. Aunque computen como visitantes internacionales, buena parte de los visitantes del resto de Cen- 
troamérica repiten las características del turista nacional en Copán: un visitante que no recurre a los operadores de turismo organizado y realiza el desplazamiento en vehículo propio, generalmente en grupos de amigos y/o familiares.

La condición de visitantes de rango regional implica el recurso generalizado al viaje independiente, pero además tiene implicaciones relativas a la distribución temporal de las visitas y el uso turístico de Copán. Estas implicaciones tienden a atenuarse conforme aumenta la distancia con respecto al lugar de procedencia, en un «continuun» que incluye desplazamientos de ocio cotidiano de los residentes en el Valle de Copán, excursiones largas con vuelta a la localidad de origen y recorridos amplios con pernoctación en uno o varios puntos del viaje.

Respecto a la distribución temporal, destaca su elevada irregularidad. A nivel diario, la visita se concentra en sábados y domingos, en especial para los visitantes de corta distancia. Además de los fines de semana, los momentos de mayor afluencia están asociados a los periodos vacacionales tradicionales, fundamentalmente la Semana Santa, cuando la presencia de visitantes de larga distancia es más importante. En relación a la pernoctación, en el $56,97 \%$ de los desplazamientos considerados no se pasaba la noche en Copán $(41,41 \%$ para el conjunto de la afluencia). Se tratan por lo tanto de excursiones desde el lugar de residencia del visitante o de una parada en un recorrido más largo en el que se opta por pernoctar en lugares diferentes a Copán. No en vano los porcentajes más elevados de excursionismo corresponden a los visitantes procedentes del propio Departamento de Copán $(63,9 \%)$, pero también en aquellos residentes en Cortés $(63,72 \%)$ e incluso en Guatemala (76,98\%). Por último, el recurso a los guías para visitar el Parque Arqueológico también es bastante reducido, un 34,61\%, prácticamente la mitad del conjunto de la afluencia $(66,55 \%)$. También los valores más reducidos corresponden a los residentes en el Departamento de Copán $(9,89 \%)$, aunque tampoco son muy altos para los que proceden de Guatemala (27,71\%), Cortés (36,18\%) e incluso Francisco Morazán (42,74\%).

\subsection{Escolares / estudiantes hondureños en viaje colectivo}

El segundo colectivo está formado por los escolares / estudiantes de origen hondureño en viaje organizado, que suponen el 25,14\% de la afluencia total. En el año 2013 se identificaron 28.284 visitantes de este tipo en 449 grupos de viaje, lo que supone un tamaño medio de 62,99 personas por grupo. Frente a los visitantes nacionales en viaje independiente, estos grupos tienen un reparto por procedencias más equilibrado, con una aportación significativa de departamentos con escasa representación de turistas independientes, caso de Choluteca, Comayagua, Santa Bárbara y Yoro. Ello denota la importancia del área arqueológica de Copán dentro del programa educativo de los centros hondureños, en tanto que su visita justifica desplazamientos de mucho más amplio recorrido que el que están dispuestos a realizar el resto de los hondureños cuando realizan sus viajes de forma independiente.

Si esta distribución territorial es una de las características más positivas de la visita en grupos de escolares / estudiantes, hay dos aspectos que resultan especialmente negativos en términos de gestión del Parque Arqueológico: el elevado tamaño medio de los grupos y la irregularidad de la distribución territorial de sus visitas. Como se ha señalado, el tamaño 
medio de estos grupos es de 62,99. Sin embargo, este promedio oculta una distribución muy polarizada. Así, a lo largo del año se registraron 67 grupos con 100 o más escolares / estudiantes que, en conjunto, movilizaron 12.008 visitantes. En términos porcentuales, supone que el 14,92\% de estos grupos están a cargo del 42,45\% de las visitas correspondientes a esta modalidad de viaje.

Respecto a la distribución temporal, la presencia de escolares / estudiantes resulta especialmente elevada durante agosto así como de jueves a sábado. De los 365 días de 2013, únicamente se registró la visita de estos grupos en 176. Durante estos días, el número de visitantes en estos grupos ascendió de promedio a 160,7 y el número de grupos de viaje a 2,55. Es más, en 47 días se superaron las 200 visitas en grupos de este tipo, conjunto de días en los que se contabilizaron $230(51,22 \%)$ grupos que movilizaron 18.541 visitas $(65,52 \%)$. El día que registró un mayor número de visitantes de este tipo fue el jueves 29 de agosto, con 1.783 visitas repartidas en 14 grupos. De forma complementaria, por encima de las 550 visitas de escolares y estudiantes, se situaron el jueves 25 de julio (794 en 6 grupos), el viernes 12 de julio (651 en 3), el sábado 10 de agosto (628 en 6), el sábado 10 de junio (590 en 6), el jueves 27 de julio (567 en 5) y el viernes 31 de mayo (565 en 4). Los finales de mes registran un elevado número de visitantes de este tipo, en especial los jueves últimos de mes en los que los grupos de escolares / estudiantes acceden de forma gratuita.

En cuanto a las características de su visita a la zona, destaca en primer lugar el elevado recurso a los guías turísticos que trabajan en el Parque. El 88,97\% de los escolares / estudiantes realizaron una visita guiada al Grupo Principal e incluso los propios grupos del departamento de Copán recurren mayoritariamente a los guías, un 79,66\%. Estas cifras reflejan la importancia de los guías turísticos como principal fuente de información «in situ», muy por encima de los docentes a cargo de los grupos. Además de las labores de información e interpretación del área arqueológica, están desarrollando una labor pedagógica que necesita ser evaluada. De otra parte, los niveles de pernoctación en la zona son reducidos, del orden de un tercio de los grupos. Y como sucede con los visitantes en viaje independiente, conforme aumenta la distancia respecto al lugar de procedencia se incrementa el recurso a la pernoctación en la zona. Así, el 11,12\% de los escolares / estudiantes de Cortés pasan la noche en Copán, el 44,78\% de Comayagua, el 79,86\% de Francisco Morazán...

\subsection{Extranjeros en viaje independiente de larga distancia}

Numéricamente, el tercer colectivo en orden de importancia está formado por los extranjeros en viaje independiente de larga distancia, que representaron el 20,15\% de la afluencia contabilizada en 2013. A lo largo del año se registró la presencia de visitantes de más de 80 nacionalidades, aunque predominaron norteamericanos y, en menor medida, europeos. Así, se contabilizaron 7.367 estadounidenses, 1.560 canadienses, 1.390 británicos, 1.258 alemanes, 1.048 franceses, 1.021 españoles, 734 italianos, 713 mexicanos, 700 australianos, 581 colombianos o 309 japoneses. En líneas generales estos viajeros acceden a la región por avión, iniciando su recorrido en Ciudad de Guatemala, San Pedro Sula, Tegucigalpa e incluso otros aeropuertos más alejados de la zona de Copán. Una vez 
en tierra, realizan recorridos de larga duración con paradas en los principales sitios de interés, con preferencia en Guatemala. Realizan los desplazamientos internos en transporte colectivo y pernoctan en establecimientos de categoría media, en razón al precio e incluso la búsqueda de un mayor contacto con las poblaciones locales. Este modelo de viaje independiente es el característico de los desplazamientos de los norteamericanos en Norteamérica, los europeos en Europa y, como se ha reflejado anteriormente, de los propios hondureños en su país.

No cabe duda de que Copán es un nodo relevante de los vagabundeos de los extranjeros en sus viajes por esta parte de Centroamérica. Para Copán resulta un componente del flujo de visita bastante positivo en relación a varios aspectos. Primeramente, debido a que su distribución temporal es bastante regular. A nivel mensual, se registra la mayor afluencia en julio $(12,18 \%)$, marzo $(11,65 \%)$ y febrero $(10,71 \%)$ y la mínima en octubre $(4,67 \%)$, septiembre $(4,84 \%)$ y noviembre $(5,31 \%)$. Por días, tampoco hay diferencias extremas entre sábados $(17,1 \%)$ y lunes $(12,7 \%)$. Y en segundo lugar, por la fuerte tendencia a la pernoctación en la zona. De hecho, el 85,9\% de los visitantes de este tipo pasó la noche en Copán, previsiblemente en una gama de establecimientos de alojamiento de muy amplio espectro. Más allá de estos aspectos generales, se hace necesario un conocimiento más exhaustivo de este tipo de visitantes, tanto en relación a la geografía de sus movimientos turísticos como del uso que hacen de la zona de Copán (tipo de alojamiento, actividades realizadas, gasto en destino...). En otro orden de cosas, el 54,89\% de estos visitantes efectuaron la visita al Grupo Principal acompañados de un guía, un valor reducido en comparación con el que registran los visitantes en viaje colectivo, ya sean nacionales o extranjeros. De hecho este tipo de visitantes es el objetivo principal de los dispositivos de información de la administración del Parque, tanto a nivel de la web (información de la zona y venta de entradas) como ya «in situ» (paneles interpretativos, folletos y mapas de la zona, etc.).

\subsection{Extranjeros en grupo organizado de agencia de viajes}

El cuarto tipo de visitante característico de Copán es el extranjero en grupo organizado de agencia de viajes, que supuso el 18,8\% de la afluencia contabilizada durante 2013 . Estos viajes derivan de la acción de las agencias, en tanto que se corresponden con grupos montados a partir de la adquisición individualizada de un paquete turístico en una agencia minorista. Cada turista compra un paquete previamente ensamblado; el grupo se monta a partir de cada una de estas compras. Más del $60 \%$ de estos viajeros son europeos, de hecho la propensión a la utilización de paquetes turísticos aumenta considerablemente cuando se trata de viajes intercontinentales. En otros términos, el 59,48\% de los europeos que pasaron por el Grupo Principal accedían en el marco de un producto organizado por una agencia, porcentaje que se reducía al 36,02\% para los norteamericanos y el 19,91\% para el resto de los americanos. La trayectoria turística de cada mercado de origen también es relevante; así junto a franceses, alemanes, canadienses, holandeses, españoles... también se contabilizaron un número elevado de rusos, polacos y de otras naciones que se han incorporado más recientemente al mercado de masas.

Existe un elevado número de agencias que incluyen dentro de sus productos la visita a Copán, agencias que han podido ser identificadas gracias al nuevo Sistema de Cómputo 
establecido en el Grupo Principal. En un primer nivel se sitúan los grandes operadores guatemaltecos (Guayacán, STP Guatemala Verdadera, Clark Tours...) que funcionan como agentes de receptivo local de los touroperadores internacionales. De forma complementaria, una serie de pequeñas agencias de Antigua venden servicios más sencillos a los turistas en desplazamiento por Guatemala. En segundo lugar se encuentran los grandes operadores de turismo internacional con fuerte orientación hacia el turismo arqueológico, ecoturismo, turismo activo... que ofertan viajes por todo el mundo. A veces se especializan por mercados (Overseas - Norteamérica, Logos Tour - Polonia, Shoestring - Holanda...) aunque hay agencias de clientela más amplia (G Adventures, Tucan Travel, etc.). Y en tercer lugar están los operadores hondureños, con fuerte presencia de las empresas radicadas en San Pedro Sula (Maya Temple Tours, Mesoamerica Travel...) y un papel destacado de agencias surgidas en Copán, sobre todo MC Tours. Los productos básicos que ofertan son los siguientes:

- Excursiones sin pernoctación. Se trata del producto más sencillo, ya que sólo incluye el desplazamiento en autobús o furgoneta, la entrada al Grupo Principal y, si acaso, el almuerzo y los servicios de guía. Diferentes operadores ofrecen este viaje saliendo desde Ciudad de Guatemala, Antigua, San Pedro Sula o incluso localidades como Tela. Se trata de un viaje largo, que alcanza las $14 \mathrm{~h}$ si el lugar de inicio está en Guatemala, ya que a la distancia hay que unir la demora del paso fronterizo.

- Circuitos cortos desde Guatemala. Producto mayoritariamente operado por agencias guatemaltecas, se trata de viajes de una duración entre dos y cuatro días en los que se combina la visita a Copán con otros lugares situados en el oriente de Guatemala: Río Dulce, Castillo de San Felipe... y por supuesto Quiriguá. Orientada a los visitantes centrados en Guatemala, son circuitos con origen y fin en Antigua o Ciudad de Guatemala.

- Circuitos cortos de Honduras, centrados en Copán. Producto propio de las agencias hondureñas, también se trata de viajes que duran entre dos y cuatro días, con la práctica totalidad de las pernoctaciones realizadas en la localidad de Copán. En la mayor parte de las ocasiones el circuito tiene su inicio en San Pedro Sula, aunque también se ofrecen desde Tela e incluso Tegucigalpa. Además del desplazamiento, la mayor parte del tiempo de viaje se centra en la estancia en Copán, con paradas ocasionales en La Entrada y la comunidad chortí La Pintada.

- Circuitos largos de Guatemala, con extensiones a los países vecinos. Se trata de viajes largos, generalmente de más de diez días. El recorrido se centra en los principales atractivos y zonas turísticas de Guatemala: Antigua, Chichicastenango, Panahachel, Lago de Atitlán, Iximche, San Juan Comalapa, Yaxha, El Ceibal, Aguateca, San Francisco El Alto... además de Tikal en el Petén, que muchas se visita como una excursión por vía aérea. La visita a Copán está asociada al oriente guatemalteco, con paradas también en Quiriguá y Río Dulce. De hecho, no siempre se realiza pernoctación en Copán ya que a veces únicamente se realiza una visita breve al Grupo Principal y se regresa a localidades vecinas de Guatemala para la pernoctación. Este tipo de productos es operado sobre todo por agencias guatemaltecas pero también lo ofertan operadores hondureños que inician o finalizan sus recorridos en San Pedro Sula. 
- Circuitos largos de Honduras. También se trata de viajes largos que superan los ocho días, organizados por diferentes operadores nacionales. La mayor parte de estos recorridos arrancan de San Pedro Sula, en función de la conectividad internacional del aeropuerto. Incluye la visita a distintas localidades de la costa Caribe (Tela, La Ceiba, Trujillo), parques nacionales (Cerro Azul Meámbar, Pico Bonito, Celaque) y centros coloniales del interior (Comayagua, Gracias, Santa Rosa de Copán), además de lugares como Tegucigalpa, el Lago de Yojoa e incluso Roatán mediante ferry o vuelo interno. La pernoctación está asociada a un número reducido de localidades, entre las que prácticamente siempre se incluye Copán (1-2 noches).

- Circuitos de ámbito centroamericano. Se corresponden con los viajes más largos de todos, con una duración que generalmente superan los quince días. Orientados al visitante de larga distancia, son operados por agencias de Guatemala, Honduras y también operadores internacionales más especializados. Durante el tiempo de viaje se visitan diferentes lugares de Belize, Guatemala, Honduras, El Salvador, Nicaragua, Costa Rica, Panamá e incluso alguno incluye zonas del sur de México.

- Otros productos más singulares. Además de los productos generalistas, distintos operadores trabajan con productos más singularizados en función de la temática o el mercado de referencia. Así encontramos viajes cortos desde El Salvador y Nicaragua, tours focalizados sobre el calendario maya, etc.

Como queda reflejado, Copán constituye uno de los espacios de referencia de los paquetes turísticos del ámbito guatemalteco y hondureño, e incluso de los viajes que toman como referencia el conglomerado centroamericano. Se trata en la mayoría de las ocasiones de viajes de temática patrimonial, con fuerte asociación con el mundo maya y visita a los grandes conjuntos arqueológicos (Tikal, Quiriguá, Joya de Cerén...), pero también distintas comunidades vivas (tierras altas de Guatemala), ciudades coloniales (Antigua, Comayagua, Granada...), grandes capitales (San Pedro Sula, Ciudad de Guatemala, Managua, El Salvador...) e incluso áreas naturales protegidas. En Copán, la distribución mensual de estas visitas es bastante irregular, con fuerte peso del periodo comprendido entre noviembre y marzo, la temporada seca caracterizada por temperaturas más suaves y ausencia de lluvias (y huracanes). En cambio, a nivel diario la distribución por días es completamente regular.

Dentro de estos viajes, Copán es un nodo indudable de pernoctación, con el 90,31\% de los visitantes que pasan al menos una noche en la localidad. El 9,68\% restante se corresponde con los excursionistas o turistas en circuito que utilizan otros lugares para pernoctar. La visita al Grupo Principal del Parque Arqueológico constituye la actividad central de la estancia y en dicha visita se recurre en más de un $99 \%$ a los guías turísticos. Aunque en la mayoría de las ocasiones se trata de guías encuadrados en las asociaciones locales, también existe cierto número de grupos que recurren a otros guías autorizados, lo que podría ser indicativo de ciertos desajustes entre las condiciones de los guías locales y los requerimientos de algunas agencias que atienden a ciertos segmentos de la demanda. De forma complementaria, generalmente planteadas como actividades adicionales sujetas a precio específico, se da la posibilidad de visitar los túneles de algunas pirámides, el 
Museo de Esculturas, la zona de Sepulturas... y, ya fuera del Parque, la comunidad de La Pintada, la Hacienda San Lucas, el Parque de Aves Montaña Guacamaya e incluso, en un paso a caballo, el yacimiento de Los Sapos.

\section{REFLEXIONES FINALES Y CONCLUSIONES}

El desarrollo de los trabajos realizados en Copán, que son la base de los datos expuestos en los epígrafes anteriores, ha permitido un avance muy significativo en el conocimiento sobre los visitantes de este sitio arqueológico del Patrimonio Mundial. El punto de partida estriba en la ausencia de un nivel de información intermedio entre las estadísticas de afluencia disponibles (de alcance limitado y escasa fiabilidad) y las monografías de campo de fuerte orientación antropológica (demasiado centradas en la percepción turística del patrimonio así como en la consiguiente generación de «discursos turísticos»). En base al Estudio de Capacidad de Carga se han diseñado e implementado una serie de operaciones de recogida de información dentro de las que destaca el nuevo Sistema de Cómputo de la Visita. Este Sistema se basa en una ficha de recogida de datos que destaca por aspectos como su sencillez: una vez entrenado el personal responsable, rellenar los campos de cada ficha-grupo de viaje ha resultado mucho más rápido y cómodo que el antiguo Libro de Registro nominal basado en la firma de cada visitante. La sencillez en todos los niveles era una condición de base para el desarrollo de los trabajos planteados. Buena parte de los grandes hitos patrimoniales orientados a la visita pública de los países más desarrollados cuentan con sistemas de registro de la visita bastante sofisticados, a partir de la dotación de personal más o menos especializado y con programas informáticos específicos. Copán se sitúa en un contexto diferente: los recursos humanos tienen nivel mínimo de formación, las instalaciones de administración y servicio son muy precarias, y son frecuentes los cortes en el suministro eléctrico, lo que disuade de depender excesivamente de sistemas informáticos. Como se ha señalado, la sencillez en el manejo era condición importante, en una lógica de cooperación al desarrollo y adecuación a las posibilidades locales de mantenimiento de las operaciones, una vez se diera por concluido el Estudio de Capacidad de Carga. Respecto a este objetivo los resultados son bastante satisfactorios: el Sistema se mantiene, ha sido presentado por la administración del Parque como ejemplo de buenas prácticas en la gestión de sitios arqueológicos y se está planteando su implantación en otros lugares de la República.

El alcance de los datos obtenidos va mucho más allá de la información que recogen los sistemas de registro de visita al uso, donde destaca la labor de instituciones como el Instituto Andaluz del Patrimonio Histórico y el Instituto Nacional de Antropología e Historia de México. Estos sistemas permiten acotar de forma adecuada el universo de la visita a parques arqueológicos, monumentos y museos, la base para la realización de encuestas mucho más específicas a una muestra representativa de visitantes. Así se elaboran los estudios de público de los referentes patrimoniales, cuya dimensión turística ha sido enfatizada en nuestro trabajos en Medina-Azahara (Calle Vaquero et al., 2008), la catedral de Santiago de Compostela (Santos et al., 2014), la necrópolis de Carmona (García Hernández et al., 2011) y la Colegiata de San Isidoro de León (García Hernández et al., 2012). El nuevo Sistema de Cómputo de Visita de Copán constituye un sistema de registro continuo 
que recoge más información que los modelos convencionales de registro pero menos que las encuestas, aunque también su coste de implantación ha sido muchísimo más reducido. En todo caso los datos ahora disponibles permiten estratificar la muestra de las posibles encuestas con las suficientes garantías.

Más allá de los aspectos de planteamiento y metodología, es momento de resaltar los resultados más notables que derivan de la interpretación del conjunto de datos recogidos en las 15.663 fichas de registro de los 112.477 visitantes contabilizados en 2013. Destaca en primer lugar la importancia del turismo nacional, que registró el 52,76\% de la afluencia de dicho año. Dado que no genera divisas, este componente del flujo apenas si es considerado por la administración turística nacional y los organismos multilaterales. En cambio aporta un número de visitantes muy elevado, en consonancia con lo que sucede en otros de los grandes referentes arqueológicos del mundo maya situados a cierta distancia de los desarrollos turísticos costeros. Dentro de este flujo interno, revisten notable importancia tanto las visitas de ámbito local-regional como los viajes en grupo de la población escolar. Los primeros utilizan el Parque como un espacio de ocio ocasional, en desplazamientos que muchas veces nutren el flujo excursionista. Llama la atención la magnitud de los segundos, por primera vez cuantificada: 28.284 personas en 449 grupos de viaje, lo que representó el $25,14 \%$ de la afluencia total. No cabe duda de la importancia de Copán, como quintaesencia del pasado maya del país, dentro del programa educativo de Honduras, de ahí los largos desplazamientos desde la práctica totalidad de la República. Este aspecto tan positivo queda empañado por la concentración de las visitas sobre determinados días del año así como el elevado tamaño medio de los grupos. Ambos aspectos, que favorecen situaciones puntuales de sobrecarga turística, deberán ser objeto de un control más específico.

Respecto al turismo extranjero, adopta perfiles mucho más heterogéneos de lo esperado. Existe en primera instancia un flujo correspondiente a los habitantes que residen en las repúblicas vecinas $(15,48 \%$ de las visitas foráneas y 7,29\% de la afluencia total), fundamentalmente Guatemala y El Salvador. En buena medida, tienen un comportamiento turístico muy similar al de los propios hondureños en su territorio: desplazamiento en vehículo propio, viaje independiente, etc. En segundo lugar es posible identificar un colectivo muy amplio de visitantes extranjeros de larga distancia en viaje independiente, colectivo que supuso el 20,15\% de la afluencia contabilizada en 2013. Vienen de América del Norte $\mathrm{y}$, en menor medida, Europa, realizando un «vagabundeo» sin prisas en los transportes colectivos del país y alojándose en establecimientos de categoría media. Su distribución temporal es extraordinariamente regular y prácticamente todos pernoctan en la localidad de Copán Ruinas. Y el tercer componente del flujo externo corresponde a los extranjeros también de larga distancia pero que viajan en grupos organizados a cargo de los operadores turísticos. Supuso el 18,8\% de la afluencia del 2013, aunque esta fórmula de viaje es especialmente importante en relación a los mercados europeos. No cabe duda de que para los visitantes que vienen desde lugares muy lejanos el destino de referencia es el mundo maya y, en un nivel más de detalle, Guatemala. En buena medida, Copán funciona como un destino de excursión desde los principales centros guatemaltecos o de pernoctación en un circuito más amplio que también tiene como referencia la cultura y civilización maya de las tierras de Guatemala. El análisis de los paquetes turísticos puestos en el mercado por los operadores ha permitido reconocer la geografía de los recorridos del turismo 
organizado y determinar la posición que tiene Copán dentro de dichos recorridos. En cambio, falta por hacer un seguimiento más exhaustivo de los viajeros independientes, sólo realizable mediante encuesta. De otra parte, llama la atención el énfasis que pone la administración turística nacional en el trabajo con los touroperadores extranjeros cuando realmente su aportación al flujo turístico no alcanza el $20 \%$.

La afluencia de visitantes al sitio arqueológico tiene notables repercusiones en la localidad de Copán Ruinas, situada a muy escasa distancia. El 58,59\% de los visitantes pernoctaron en la localidad, porcentaje que se eleva hasta el $81,38 \%$ para los extranjeros. Estos turistas son atendidos por una oferta local que está experimentando un notable crecimiento y diversificación. En la actualidad, la planta de alojamiento se compone de 48 establecimientos con aproximadamente 776 habitaciones. Existen desde hoteles convencionales orientados a los viajeros en grupo organizado hasta pequeños albergueshostales para mochileros, pasando por hotelitos con encanto y antiguas haciendas situadas fuera del núcleo urbano. Adicionalmente, el Sistema de Información Turística Georeferenciado de Honduras (SIGTUR) recoge la existencia en el municipio de 53 restaurantes, 29 tiendas de artesanía y 32 guías turísticos. Si bien la mayor parte de la actividad turística sigue pivotando sobre el Parque Arqueológico, ha aparecido una oferta turística complementaria que incluye establecimientos balnearios, escuelas de español para extranjeros, avistamiento de aves en zonas forestales y paquetes combinados centrados en la experiencia del café.

En otra ocasión hemos señalado las alianzas, contradicciones y conflictos que se producen entre patrimonio y turismo, un conjunto de relaciones complejas que se vislumbran con especial intensidad en el sitio de Copán (Calle Vaquero, 2014). Como en muchos otros lugares, buena parte de los equívocos derivan de la ausencia de un conocimiento real de los visitantes. A partir de las inciertas estadísticas disponibles, el equipo que evaluó el impacto del proyecto del aeródromo de Río Amarillo estimaba una afluencia de visitantes al Parque Arqueológico para 2022 que rondaba las 350.000 personas. Proyecciones anteriores, que utilizaban las mismas fuentes, planteaban incluso alcanzar los 500.000 visitantes. Estas cifras, realmente poco sustentadas, motivaron la respuesta del Centro del Patrimonio Mundial y otras entidades de salvaguarda patrimonial. Si el Parque tiene problemas puntuales para el manejo del uso público en el momento actual, una afluencia de dichas dimensiones implicaría una absoluta superación de su capacidad de carga. Más recientemente, en las presentaciones de los actos vinculados a la celebración en 2012 del 13 Baktun se señalaba una afluencia estimada que alcanzaría los 300.000 visitantes, en su mayor parte extranjeros. Estas estimaciones, que justificaron gastos asombrosos en promoción internacional y eventos relativos «al fin del mundo según la profecía maya», contrastaron con la cifra real de visitantes, 120.357. Y como sucedió en otros lugares del mundo maya, la mayor parte del crecimiento derivaba de la demanda turística interna. En suma, estos y otros ejemplos justifican nuestros planteamientos de la necesidad de un conocimiento adecuado de los visitantes de sitios como Copán, un conocimiento que permita una gestión del uso público que garantice la salvaguarda patrimonial del lugar y que, de forma paralela, sustente operaciones de desarrollo turístico ajustadas a las posibilidades reales del lugar en relación a su posición en los distintos mercados. 


\section{BIBLIOGRAFÍA}

BARBORAK, J.R.; MORALES, R.; MACFARLAND, C. (1984): Plan de Manejo y Desarrollo del Monumento Nacional Ruinas de Copán, Sitio de Patrimonio Cultural Mundial. Turrialba (Costa Rica), Centro Agronómico Tropical de Investigación y Enseñanza, Departamento de Recursos Naturales Renovables.

BROWN, D.F. (1999): «Mayas and tourists in the Maya World», Human Organization, vol. 58, nº 3, pp. 295-304.

CALLE VAQUERO, M. de la (2014): «Patrimonio y turismo en Copán (Honduras): alianzas, contradicciones y conflictos a distintas escalas», en F. López Palomeque y G. Cànoves Valiente (eds.), Turismo y territorio. Innovación, renovación y desafíos. Valencia, Ed. Tirant Humanidades, pp. 429-442.

CALLE VAQUERO, M. DE LA y GARCÍA HERNÁNDEZ, M. (2008). «Turismo cultural en viaje de grupo organizado. Medina Azahara / Madinat al-Zahra como referente», Cuadernos de Turismo, $\mathrm{n}^{\circ} 22$, pp. 79-99.

CASTAÑEDA, Q.E. (1995). «La economía «escritural» y la invención de las culturas mayas en el «museo» de Chichen Itza», Revista Española de Antropología Americana, $\mathrm{n}^{\mathrm{o}} 25$, pp. 181-203.

CASTAÑEDA, Q.E. (1996). In the museum of Maya cultura. Touring Chichén Itzá. University of Minnesota Press. Minneapolis.

CASTAÑEDA, Q.E. (2009): «Heritage and indigeneity: transformations in the politics of tourism», en Cultural Tourism in Latin America. The Politics of Space and Imagery. Leiden, Brill, pp. 263-298.

CÓRDOBA Y ORDOÑEZ, J. (2009): «Turismo, desarrollo y disneyzación: ¿Una cuestión de recursos o de ingenio», Investigaciones Geográficas, Boletín del Instituto de Geografía, UNAM, no 70, pp. 33-54.

CÓRDOBA Y ORDÓÑEZ, J., GARCÍA DE FUENTES, A., CÓRDOBA AZCÁRATE, M. y AYALA ARCIPRESTE, E. (2004): «Efectos locales de políticas globales: Celestún y «su» Reserva de la Biosfera (Yucatán, México)», Anales de Geografía de la Universidad Complutense de Madrid, $\mathrm{n}^{\circ}$ 24, pp. 55-78.

DALTABUIT GODÁS, M., CISNEROS REYES, H.B. y VALENZUELA VALDIVIESO, E. (2007): Globalización y sustentabilidad. El turismo en el sur de Quintana Roo. Cuernava, UNAM.

GARCÍA DE FUENTES, A. (1979): Cancún: turismo y subdesarrollo regional. México, UNAM.

GARCÍA HERNÁNDEZ, M. (2012): «Capacidad de carga turística y gestión de la visita pública en la Zona Arqueológica de Copán (Honduras)», en Actas del XV Encuentro Internacional de Latinoamericanistas Españoles «América Latina: la autonomía de una región». Madrid, Trama Editorial-CCEIB, pp. 911-921.

GARCÍA HERNÁNDEZ, M. y CALLE VAQUERO, M. DE LA (2012): «Los hitos patrimoniales en dimensión turística. Castilla y León y la Real Colegiata de San Isidoro», Polígonos, $\mathrm{n}^{\circ} 23$, pp. 113-145.

GARCÍA HERNÁNDEZ, M;, CALLE VAQUERO, M. DE LA y MÍNGUEZ GARCÍA, M.C. (2011). «Capacidad de carga turística y espacios patrimoniales. Aproximación a 
la estimación de la capacidad de carga del Conjunto Arqueológico de Carmona (Sevilla, España)», Boletín de la Asociación de Geógrafos Españoles, n 57, pp. 219-242.

GARCÍA TARGA, J. (2012): «Los parques ecoarqueológicos en el área maya: algunos aspectos de su gestión», Estudios de Cultura Maya, Vol. XXXIX, pp. 227-247.

GARRETT, W.E. (1989): «La Ruta Maya», National Geographic, vol. 176, n 4, pp. 424-479.

HERNÁNDEZ CRUZ, R.E., BELLO BALTAZAR, E., MONTOYA GÓMEZ, G. y ESTRADA LUGO, E.I.J. (2005): «Social adaptation. Ecotourism en the Lacandon Forest», Annals of Tourism Research, vol. 32, n 3, pp. 610-627.

HERNANDEZ LOPEZ, E. (2012): «La percepción de un multidestino a partir de la visión de los operadores turísticos en Francia» en Actas del II Simposio de Becarios y Exbecarios del CONACyT Edición Europa. Estrasburgo, 29-30 Noviembre 2012. Casa Universitaria Franco-Mexicana. Disponible en http://www.mufm.fr/sites/mufm. univ-toulouse.fr/files/evenement/symposium/ponencias/enrique_hernandez_lopez.pdf (fecha de consulta: 12 mayo 2014).

INSTITUTO HONDUREÑO DE ANTROPOLOGÍA E HISTORIA (2005). Plan de Manejo Zona Arqueológica de Copán. Tegucigalpa, Instituto Hondureño de Antropología e Historia (IHAH).

JUAREZ, A.M. (2002): «Ecological degradation, global tourism, and inequality: maya interpretations of the changing environment in Quintana Roo, Mexico», Human Organization, vol. 61, $\mathrm{n}^{\mathrm{o}} 2$, pp. 113-124.

MAGNONI, A., ARDREN, T. y HUTSON, S. (2007): «Tourism in the Mundo Maya: inventions and (mis)representation of maya identities and heritage», Archaelogies, vol. 3, n 3 , pp. 353-383.

MARÍN GUARDADO, G. (2010): «Turismo, globalización y mercantilización del espacio y la cultura en la Riviera Maya: un acercamiento a tres escenarios», en Etnia, lengua y territorio. El sureste ante la globalización. Mérida, UNAM, pp. 17-55.

MARTÍ, F. (1985). Cancún, fantasía de banqueros. La construcción de una ciudad turística a partir de cero. Editado por el autor.

MEDINA, L.K. (2003): «Commoditizing culture. Tourism and maya identity», Annals of Tourism Research, vol. 30, $\mathrm{n}^{\mathrm{O}}$ 2, pp. 353-368.

MINGUEZ GARCÍA, C. y SEGRADO PAVÓN, R. (2012): «La gestión de la visita en los conjuntos arqueológicos mayas en Quintana Roo, México», en Actas del XV Encuentro Internacional de Latinoamericanistas Españoles «América Latina: la autonomía de una región». Madrid, Trama Editorial-CCEIB, Adenda.

MORTENSEN, L. (2001): «Las dinámicas locales de un patrimonio global: arqueoturismo en Copán, Honduras», Mesoamérica, n 42, pp. 104-134.

MORTENSEN, L. (2009): «Fronteras sin marcar: contextos de la arqueología de Copán», Yaxkin, Vol. XXV, No 2, pp. 87-109.

MORTENSEN, L. (2011): «Copan past and present: maya archaelogical tourism and the Chorti in Honduras», en The Ch'orti'Maya Area: Past and Present. Gainesvilles, University Press of Florida, pp. 246-257.

MUÑOZ COSME, G. y VIDAL LORENZO, C. (2003a): «Patrimonio arqueológico y turismo», en XVI Simposio de Investigaciones Arqueológicas en Guatemala 2002 
(editado por J.P. Laporte, B. Arroyo, H. Escobedo y H. Mejía), Guatemala, Museo Nacional de Arqueología y Etnología, pp. 55-60.

MUÑOZ COSME, G. y VIDAL LORENZO, C. (2003b): «El impacto del turismo en las ruinas de Tikal, Guatemala», en II Congreso Internacional sobre Musealización de Yacimientos Arqueológicos. Nuevos Conceptos y Estrategias de Gestión y de Comunicación (editado por J. Beltrán de Heredia), Barcelona: Museo de Historia de la Ciudad, pp. 347-351.

ORTEGA MUÑOZ, A. (Coord.) (2010): Zonas arqueológicas: ¿valor, conservación y beneficio?. Relaciones de economía, identidad, hegemonía e impacto del desarrollo turístico. Chetumal, Centro INAH Quintana Roo.

SANTANA, R., SALVATIERRA IZABA, B., PARRA VAZQUEZ, M.R. y ARCE IBARRA, A.M. (2013): «Aporte económico del ecoturismo a las estrategias de vida de grupos domésticos de la Península de Yucatán, México», Pasos. Revista de Turismo y Patrimonio Cultural, vol. 11, n ${ }^{\circ}$ 1, pp. 185-204.

SANTOS SOLLA, X. y PENA CABRERA, L. (2014). «Management of Tourist Flows. The Cathedral of Santiago de Compostela», Pasos. Revista de Turismo y Patrimonio Cultural, vol. 12, n 4, pp. 719-735.

SANTOS LOBO, H.A; TRAJANO, E.; ALCÂNTARA MARINHO, M.; BICHUETTE, M.L.; BASSO SCALEANTE, J.A.; FURQUIM SCALEANTE, O.A.; NAZARÉ ROCHA, B.; VILLELA LATERZA, F. (2013): «Projection of tourist scenarios onto fragility maps: Framework for determination of provisional tourist carrying capacity in a Brazilian show cave», Tourism Management, vol. 35, pp. 234-243.

SEGRADO PAVÓN, R.; SERRANO BARQUÍN, R.; MÍNGUEZ GARCÍA, M.; CRUZ JIMÉNEZ, G.; JUAN PÉREZ, J.I. (2013): «Estrategias de control de impactos turísticos en las Áreas Naturales Protegidas y Zonas Arqueológicas de Quintana Roo, México», CULTUR Revista de Cultura y Turismo, n 3, pp. 6-30.

STEPENS, J.L. (1841): Incidents of Travel in Central America, Chiapas, and Yucatan. 2 vols. Frederick Catherwood (Illus.). New York, Harper \& Brothers.

TZUC SALINAS, H. (2012): «Uso turístico y revaloración del patrimonio arqueológico. El caso de Chacchoben, Quintana Roo», en Turismo, globalización y sociedades locales en la península de Yucatán, México. La Laguna (Tenerife), PASOS, Colección PASOS Edita n ${ }^{\circ}$, pp. 157-172.

VAN DEN BERGHE, P.L. (1995): «Marketing Mayas. Ethnic tourism promotion in Mexico», Annals of Tourism Research, vol. 22, n 3, pp. 568-588.

WALKER, C. (2005): «Archaeological tourism: looking for answers along Mexico's Maya Riviera», NAPA Bulletin, $\mathrm{n}^{\circ}$ 23, pp. 60-76.

WOODFILL, B. (2013): «Community development and collaboration at Salinas de los Nueve Cerros, Guatemala», Advances in Archaeological Practice: A Journal of the Society for American Archaeology, nov. 2013, pp. 105-120.

ZORRILLA MARTÍNEZ, A. (2011). «Mundo Maya: una marca con valor», Cuadernos del Patrimonio Cultural y Turismo, $\mathrm{n}^{\circ} 18$, pp. 151-159. 
